\title{
Modelling the volatility-timing of funds under CPF investment theme
}

\author{
X. Shen ${ }^{a}$, A.K. Tsui ${ }^{a}$ and Z.Y. Zhang $\underline{\underline{b}}$ \\ ${ }^{a}$ Department of Economics, National University of Singapore, Singapore \\ ${ }^{b}$ School of Business, Edith Cowan University, Australia \\ Email: zhaoyong.zhang@ecu.edu.au
}

\begin{abstract}
The performance measure of funds has been an important topic in the past few decades. In recent years the conditional models on return and volatility have become popular in studying the funds' performance measure, but most of these studies focus on the US funds and a few on the Asian-based funds. The purpose of this study is to examine the volatility-timing performance of Singapore-based funds under the CPF (Central Provident Fund) Investment Scheme and non-CPF linked funds by taking into account of the currency risk effect on internationally managed funds.
\end{abstract}

The CPF investment scheme was introduced in 1986 by the Singapore government in order to enhance CPF members' funds for retirement. CPF members usually withdraw money for house purchase, while male and high income earners involve in more risky investment with their CPF saving. The CPF board sets up strict admission criteria for investment products, especially for funds which tend to enter the CPF investment scheme. Fund management companies with intention to enter the CPF Investment must have at least S\$500 million fund managed in Singapore with minimum three fund managers. One of fund managers must have at least 5 year experience in fund management. Moreover, foreign funds recognized by the Monetary Authority of Singapore (MAS) are allowed to apply for the inclusion of CPF investment scheme, provided that they are a member of the Investment Management Association of Singapore and also have to submit a representative agreement of foreign funds or their mangers. There are 28 fund management companies under the current CPF investment scheme. Since 1 February 2006, the revised benchmark requires new-entry funds to be above the top $25 \%$ among their global peers. Compared with the existing funds within the risk level under CPF Investment Scheme, new funds are also required to have lower-than-median expense ratio. A good historical performance for at least 3 years is desirable. In addition, sales charges for fund under CPF Investment Scheme must be less than 3\% from 1 Jul 2007.

Given the strict entry criteria, it is an interesting question to ask if the CPF funds are "safer and better performed funds" as people expected. In this study we empirically assess whether the funds under CPF Investment Scheme outperform non-CPF funds by examining the volatility-timing performance associated with these funds. The volatility-timing ability of CPF funds will provide CPF board with a new method for risk classification. In particular, we employ the GARCH models and modified factor models to capture the response of funds to the market abnormal conditional volatility including the week day effect. The SMB and HML factors for non-US based funds are constructed from stock market data to exclude the contribution of size effect and BE $\backslash M E$ effect. The results show that volatility timing is one of the factors contributing to the excess return of funds. However, the funds' volatility-timing seems to be country-specific. Most of the Japanese equity funds and global equity funds under CPF investment scheme are found to have the ability of volatility timing. This finding contrasts with the existing studies on Asian ex-Japan funds and Greater China funds. Moreover, there is no evidence that funds under CPF Investment Scheme show a better group performance of volatility timing.

Keywords: volatility timing, GARCH, weekday effect, currency risk exposure 


\section{INTRODUCTION}

The performance measure of funds has been an important topic in the past few decades. The conventional approach is to measure the performance of funds by calculating their absolute returns or reward-to-risk ratio (Sharpe, 1966). Market timing has become an important measure to evaluate the performance of fund managers and an important skill for fund managers to make dynamical investment portfolio (Treynor and Mazuy, 1966, Jensen, 1972). In recent years the conditional models on return and volatility have become popular in studying the funds' performance measure (Busse, 1999). Volatility timing is a trading strategy which focuses on the future volatility of the investment portfolio. Studies find that many portfolio managers behave like volatility timers, reducing their market exposure during periods of high expected volatility. However, most of these studies focus on the US funds and a few on the Asian-based funds. The purpose of this study is to examine the volatility-timing performance of Singapore-based funds under the Central Provident Fund (CPF) Investment Scheme and non-CPF linked funds by taking into account of the currency risk effect on internationally managed funds.

The CPF investment scheme was introduced in 1986 by the Singapore government in order to enhance CPF members' funds for retirement. CPF members usually withdraw money for house purchase, while male and high income earners involve in more risky investment with their CPF saving (see Koh et al., 2007). There are two accounts under the current CPF investment scheme, namely ordinary account (OA) and special account (SA). Through OA and SA, CPF members can invest in insurance, unit trust, exchange traded funds (ETFs), fixed deposits, bond, treasury bills, fixed deposits, shares, property funds and gold. The investible products under CPF-OA and CPF-SA are different, as only selected unit trusts, ETFs and investment-linked insurance products can be invested under the CPF-SA. The instruments under CPF-SA are usually regarded to have higher risk than those under CPF-OA. To become a member of CPF investment scheme, investors are required to have 20,000 SGD in CPF-OA or 20,000 SGD in CPF-SA. When the CPF investment scheme was first introduced, members were allowed to invest up to $20 \%$ of their CPF-OA saving. There are different investible ratios according to the assets risk classes. Under current CPF-OA, investible ratio for shares, property funds and corporate bonds are up to 35\%, and investible ratio for gold ETFs and other gold products are $10 \%$.

The CPF board sets up strict admission criteria for investment products, especially for funds which tend to enter the CPF investment scheme. Fund management companies with intention to enter the CPF Investment must have at least S\$500 million fund managed in Singapore with minimum three fund managers. One of fund managers must have at least 5 year experience in fund management. Moreover, foreign funds recognized by the Monetary Authority of Singapore (MAS) are allowed to apply for the inclusion of CPF investment scheme, provided that they are a member of the Investment Management Association of Singapore and also have to submit a representative agreement of foreign funds or their mangers. There are 28 fund management companies under the current CPF investment scheme, and 11 insurers under CPF Investment Scheme. Insurers can also provide members with investment-linked products if they fulfill similar important admission criteria. Since 1 February 2006, the revised benchmark requires new-entry funds to be above the top $25 \%$ among their global peers. Compared with the existing funds within the risk level under $\mathrm{CPF}$ Investment Scheme, new funds are also required to have lower-than-median expense ratio. A good historical performance for at least 3 years is desirable. In addition, sales charges for fund under CPF Investment Scheme must be less than 3\% from 1 Jul 2007.

Given the strict entry criteria, it is an interesting question to ask if the CPF funds are "safer and better performed funds" as many people expected. In this study we empirically assess whether the funds under CPF Investment Scheme outperform non-CPF funds by examining the volatility-timing performance associated with these funds. In particular, we employ the GARCH models and modified factor models to capture the response of funds to the market abnormal conditional volatility including the week day effect. The SMB and HML factors for non-US based funds are constructed from stock market data to exclude the contribution of size effect and BE\ME effect. The volatility-timing ability of CPF funds will provide CPF board with a new method for risk classification. Currently the CPF board ranks funds' cumulative return within the same risk classification, namely, (1) higher risk which includes funds invested in equities, (2) medium to high risk which includes funds in a mix of equities and bonds, (3) low to medium risk includes funds invested in income products and bonds, and (4) low risk includes funds invested in money market products. However, this method is too board to evaluate the funds' market risk management and the impact on the returns of the funds. This is also the first study to apply the GARCH family models to the performance measure of the Singapore-based funds with the inclusion of currency risk to capture the characteristics of internationally 
managed funds. The results show that volatility timing is one of the factors contributing to the excess return of funds. However, the funds' volatility-timing seems to be country-specific. Most of the Japanese equity funds and global equity funds under CPF investment scheme are found to have the ability of volatility timing. This finding contrasts with the existing studies on Asian ex-Japan funds and Greater China funds. Moreover, there is no evidence that funds under CPF Investment Scheme show a better group performance of volatility timing.

The rest of this study is organized as follows. Section 2 discusses the models and the methodology used in this study. Section 3 analyzes the data sets, and discusses the empirical results. Section 4 concludes.

\section{METHODOLOGY AND THE MODEL}

In this section we first discuss the volatility-timing model and then the methodology for conducting the empirical study. Treynor and Mazuy (1966) introduced a market-timing model to study whether mutual funds can outperform the market. Their model is based on the assumption that fund managers will shift to lessvolatile assets when the market is bad and shift to more-volatile assets when the market is good. Therefore, a fund which can consistently outperform the market will have a "characteristic line" with steep slope when the market return is positive, or with a smooth slop when the market is negative. The slope of characteristic line describes the effective volatility of funds, which in turn contributes to the high return of funds. However, none of the 57 mutual funds in their sample is found to outperform the market. Sharpe (1966) extended this model by introducing a reward-to-risk ratio. Reward-to-risk ratio measures funds' return in terms of risks. An alternative market-timing model was proposed by Merton and Henriksson (1981). Their main assumption is that fund managers predict when they believe market return will excess the risk-free rate. Measures of performance that attempt to accommodate market timing behavior typically model the ability to time the level of market factors, but not market volatility. Investors value market level timing because the positive covariance between a fund's market exposure and the future market return boots the expected portfolio return for a given average risk exposure. Risk-averse investors value volatility timing when funds can reduce market exposure in anticipation of higher volatility. The negative covariance between a fund's market exposure and volatility lowers the average volatility of the portfolio, and can do so without an average return penalty. Busse (1999) studies volatility timing behavior in US mutual funds, and finds evidence for the behavior in funds' returns. Following Busse (1999), we specify the single-factor model as follows:

$$
R_{p t}=\alpha_{p}+\beta_{m p} R_{m t}+\varepsilon_{p t}
$$

where $R_{p t}$ is the excess return of individual fund at time $\mathrm{t}$ and $R_{m t}$ is the excess return of market at time $\mathrm{t}$,

$\alpha_{p}$ is the abnormal return of the fund, $\beta_{m p}$ is the exposure of the fund to the market risk, and $\varepsilon_{i, t+1}$ is the idiosyncratic return of the fund at time t. To account for volatility timing, a simplified Taylor series expansion is used to transfer the market beta into a linear function of the difference between market volatility and it time-series mean:

$$
\beta_{m p t}=\beta_{0 m p}+\gamma_{m p}\left(\sigma_{m t}-\bar{\sigma}_{m}\right)
$$

By substituting Eq. (2) into Eq. (1), we can get the daily single-index volatility timing model as follows.

$$
R_{p t}=\alpha_{p}+\beta_{0 m p} R_{m t}+\gamma_{m p}\left(\sigma_{m t}-\bar{\sigma}_{m}\right) R_{m t}+\varepsilon_{p t}
$$

where $\gamma_{m p}$ is the volatility timing coefficient, which captures the relation between market volatility and fund return contributed to fund manager's volatility-timing ability, and $\sigma_{m t}$ is the standard deviation of the market index. Let $E_{t-1}\left(R_{m t}\right)$ be the expected return of market index conditional on the information set at time $\mathrm{t}-1$, if $\partial E_{t-1}\left(R_{m t}\right) / \partial \sigma_{m t} \leq 0$, we expect a negative $\gamma_{m p}$ if the fund manager is skillful at volatility timing. That is to say, when the market volatility is higher than its time-series mean, a fund manager good at volatility timing can predict the increasing market volatility in advance and then adjust the assets from high volatile securities to low volatile securities. In other words, the individual fund with good volatility timing would be more sensitive to the market when the market is less volatile, while it would be less sensitive to the market 
when the market is more volatile. This process generates returns for the fund. On the other hand, if $\partial E_{t-1}\left(R_{m t}\right) / \partial \sigma_{m t}>0$ for the market index, a positive volatility-timing coefficient is expected for a fund manager who is good at volatility timing.

For a regional or global fund, the return is reported in a domestic currency on a daily basis while the actual trading in the foreign countries is invoiced and settled in foreign currencies. The domestically reported return is exposed to the currency risk. To correct the biased estimates of the market beta, we take account of the foreign exchange risk and follow Jensen (1969) and Lim (2005) to specify the currency-adjusted international CAPM model as follows:

$$
E_{t}\left(R_{t+1}^{S G}-r f_{t+1}^{F C}\right)=\beta_{t} E_{t}\left(R_{m t}^{F C}\right)+E_{t}\left(\Delta s_{t+1}^{S G}-\Delta \pi_{t+1}^{S G}\right)
$$

where $R_{t+1}^{S G}$ is the excess return of funds invested in foreign country but reported in Singapore dollars, $r f_{t}$ is the risk-free rate in the foreign country, $S_{t+1}^{S G}$ is the spot exchange rate at time $t+1$, which is defined as the amount of Singapore Dollar per foreign currency, and $\pi_{t+1}^{S G}$ and $\pi_{t+1}^{F C}$ are respectively the inflation rate at time $\mathrm{t}+1$ for domestic country and foreign country. $\Delta s_{t+1}^{S G}=\ln \left(S_{t+1}^{S G}\right)-\ln \left(S_{t}^{S G}\right)$ is the nominal change of exchange rate, and $\Delta \pi_{t+1}^{S G}=\pi_{t+1}^{S G}-\pi_{t+1}^{F C}$ refers to the inflation rate differential between Singapore and the foreign country.

Instead of using the conventional moving-average volatility, we employ the conditional variance generated from the GARCH family to describe the market volatility. A comprehensive survey and detailed theoretical aspects of multivariate GARCH models can be found in McAleer (2005). We adopt a fitted EGARCH or GARCH with adjusted mean equation and assumed error term to generate the conditional variance for different benchmark series. The proposed GARCH framework to estimate the volatility timing coefficients of funds are specified as follows:

$$
\begin{gathered}
R_{m t}=\phi_{0}+\sum_{i=1}^{p} \phi_{i} R_{m, t-i}+\varepsilon_{t}-\sum_{i=1}^{q} \theta_{i} \varepsilon_{t-i}, \text { where } R_{m t}=r_{m t}-r_{f t} \\
\varepsilon_{m t} \mid \varepsilon_{m, t-1}, \varepsilon_{m, t-2}, \ldots \sim N\left(0, \sigma_{m t}^{2}\right) \text { or } t\left(0, \sigma_{m t}^{2}\right) \\
\ln \sigma_{m t}^{2}=a_{0}+\sum_{i=1}^{s} \alpha_{i} \frac{\left|\varepsilon_{m, t-i}\right|+\gamma_{i} \varepsilon_{m, t-i}}{\sigma_{m, t-i}}+\sum_{j=1}^{m} \beta_{j} \ln \sigma_{m . t-j}^{2} \\
\text { Or }, \sigma_{m t}^{2}=a_{0}+\sum_{i=1}^{m} a_{i} \varepsilon_{m, t-i}^{2}+\sum_{j=1}^{s} b_{j} \sigma_{m, t-j}^{2} \\
R_{p t}=\alpha_{p}+\sum_{k=1}^{K} \beta_{k p} R_{k t}+\gamma_{m p}\left(\sigma_{m t}-\bar{\sigma}_{m}\right) R_{m t}+\beta_{c t} R_{c t}+\varepsilon_{p t}
\end{gathered}
$$

where $k=1,2,3$ and $R_{c t}=\Delta s_{t+1}^{S G}-\Delta \pi_{t+1}^{S G}-r_{f t}$

Equation (5) is the typical autoregressive generating process for market index. Equation (6) assumes the error term follows a conditional normal distribution with zero mean and conditional variance $\sigma_{m t}^{2}$. Equation (7) and Equation (8) accommodate the conditional variance in a GARCH or EGARCH framework. The choice of GARCH or EGARCH depends on the fitness of series. Equation (9) is the modified factor model to analyze the response of funds to abnormal market volatility. When we consider more factors in the model, we follow Fama and French (1993) to include terms that capture the differential dynamics of small cap stocks relative to large cap stocks (SMB) and high book-to-market stocks relative to low book-to-market stocks (HML) in addition to the market factor. Thus, when $\mathrm{k}=1$, the excess return of the market index is the only factor considered except the excess return of exchange rate change; when $k=2$, the excess return of the market and HML are the loaded factors; when $\mathrm{k}=3$, the excess return of the market, SMB and HML are included in the model besides the excess return of exchange rate change. 
Shen et al., Modelling the volatility-timing of funds under CPF investment scheme

\section{EMPIRICAL ANALYSIS}

\subsection{Data Description}

The funds chosen for this study are confined to those available in the Singapore fund market, whether they are managed offshore or managed locally. Time series data are obtained from Bloomberg, while the categories of regional, country and global funds are from IMAS Fund Information Service. Only equity funds are considered because of unavailability of benchmarks about bonds. Newly launched funds after 2006 are excluded because of the short duration. The daily return of funds is calculated as,

$R_{\text {fund, },}=\frac{N A V_{t}-N A V_{t-1}}{N A V_{t-1}} \cdot$

where $N A V_{t}$ is the daily net asset value. We do not include dividends as a part of return, because the funds' dividend is not easily available. Similarly, the daily returns of CPF funds are taken natural log to get the continuously compounded return. The excess return of CPF funds is defined as.

$$
R_{p t}=\ln \left(\frac{N A V_{t}}{N A V_{t-1}}\right)-\ln \left(1+r f_{t}\right)
$$

Although there are 7 Japan equity funds under CPF Investment Scheme and 6 non-CPF Japan equity funds, we use 5 funds under CPF Investment Scheme and 4 Non-CPF funds because the rest have insufficient number of observations. Similarly, we could only include $7 \mathrm{CPF}$ global equity funds and 7 non-CPF global equity funds. In the case of Asian ex-Japan equity fund, there are 15 funds under CPF investment scheme and 10 non-CPF funds. But due to the data availability issue, we could include in our dataset only $10 \mathrm{CPF}$ funds and 4 non-CPF Asian ex-Japan equity funds. Again, five out of $8 \mathrm{CPF}$ funds and 2 out of 3 non-CPF funds are included in dataset for the Greater China equity funds. All data are daily and the sample period for the Japanese equity funds, global equity funds and Asian ex-Japan equity funds ranges from 1 January 2000 to 31 December 2006, and for the Greater China equity funds from 1 January 2000 to 31 December 2007.

We use the stock index of the concerned country as the proxy for market index, and the major regional or global index used in the funds' factsheets as the benchmark index of the invested market. Daily excess returns of markets are generated by: $R_{m t}=\ln \left(\frac{P_{m t}}{P_{m, t-1}}\right) \times 100-\ln \left(1+r f_{t}\right) \times 100$

where $P_{m t}$ is the daily index of the market. MSCI Japan, MSCI world, MSCI Asian ex-Japan and MSCI Golden Dragon are chosen as the market benchmarks for Japan equity funds, global equity funds, Asian ex-Japan equity funds and Greater China equity funds, respectively

\begin{tabular}{|c|c|c|c|c|}
\hline \multirow{3}{*}{ Funds } & \multicolumn{2}{|c|}{ Without currency risk } & \multicolumn{2}{|c|}{ With currency risk } \\
\hline & \begin{tabular}{|l|} 
Single-index \\
\end{tabular} & Three-index & Single-index & Three-index \\
\hline & $\gamma_{m p}$ & $\gamma_{m p}$ & $\gamma_{m p}$ & $\gamma_{m p}$ \\
\hline \multirow[t]{2}{*}{ Fund 1} & -0.041 & -0.048 & -0.074 & -0.082 \\
\hline & $(0.95)$ & $(1.10)$ & $(1.77)$ & (1.96)* \\
\hline \multirow[t]{2}{*}{ Fund 2} & -0.071 & -0.077 & -0.112 & -0.121 \\
\hline & $(1.54)$ & $(1.70)$ & (2.57)* & $(2.78)^{* *}$ \\
\hline \multirow[t]{2}{*}{ Fund 3} & 0.057 & 0.039 & 0.010 & -0.011 \\
\hline & $(1.30)$ & $(0.90)$ & $(0.25)$ & $(0.27)$ \\
\hline \multirow[t]{2}{*}{ Fund 4} & -0.155 & -0.173 & -0.128 & -0.145 \\
\hline & (2.29)* & $(2.55)^{*}$ & $(1.91)$ & $(2.16)^{*}$ \\
\hline \multirow[t]{2}{*}{ Fund 5} & -0.060 & -0.085 & -0.106 & -0.133 \\
\hline & $(1.17)$ & $(1.72)$ & $(2.16)^{*}$ & $(2.84)^{* *}$ \\
\hline $\bar{\gamma}_{m p}$ & -0.155 & -0.173 & -0.109 & -0.121 \\
\hline
\end{tabular}

Table 2: Volatility-timing coefficients for non-CPF Japan equity funds

\begin{tabular}{|l|l|l|l|l|}
\hline \multirow{2}{*}{ Funds } & \multicolumn{2}{|c|}{ Without currency risk } & \multicolumn{2}{c|}{ With currency risk } \\
\cline { 2 - 5 } & Single-index & Three-index & Single-index & Three-index \\
\cline { 2 - 5 } & $\gamma_{m p}$ & $\gamma_{m p}$ & $\gamma_{m p}$ & $\gamma_{m p}$ \\
\hline Fund 1 & -0.048 & -0.080 & -0.099 & -0.134 \\
\hline & $(0.83)$ & $(1.50)$ & $(1.79)$ & $(2.64)^{* *}$ \\
\hline Fund 2 & -0.016 & -0.054 & -0.017 & -0.057 \\
\hline & $(0.41)$ & $(1.55)$ & $(0.44)$ & $(1.61)$ \\
\hline Fund 3 & -0.032 & -0.040 & -0.031 & -0.040 \\
\hline & $(1.18)$ & $(1.49)$ & $(1.15)$ & $(1.48)$ \\
\hline Fund 4 & -0.064 & -0.090 & -0.090 & -0.118 \\
\hline & $(1.52)$ & $(2.19)^{*}$ & $(2.17)^{*}$ & $(2.93)^{* *}$ \\
\hline$\gamma_{m p}$ & N/A & -0.090 & -0.090 & -0.126 \\
\hline Note: (Absolute values of t statistics are in parentheses) * significant at \\
$5 \% \cdot * *$ significant at 1\%
\end{tabular}

$5 \%$; ** significant at $1 \%$

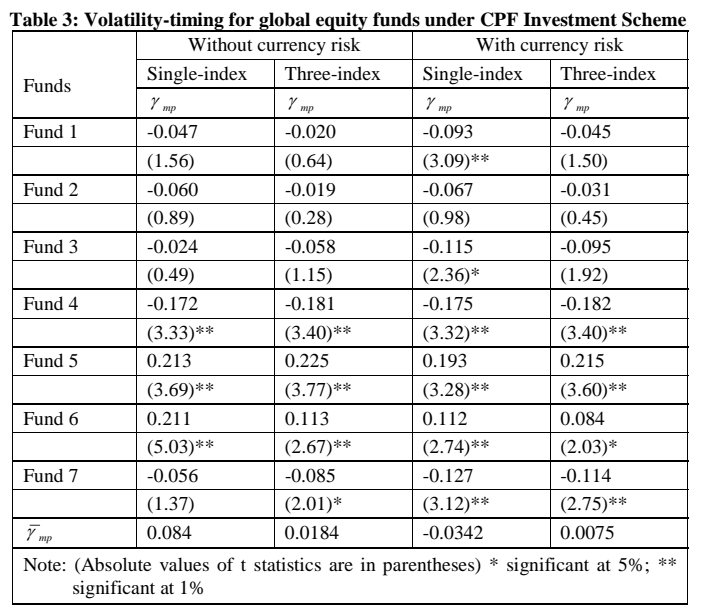


Shen et al., Modelling the volatility-timing of funds under CPF investment scheme

\subsection{Empirical Results}

We have assessed the property of the concerned variables used in this study, and the results confirm that the all the series are $\mathrm{I}(0)$ process (results available upon request). We then estimate the mean equation for each of the market indices to assess the week day effect on the excess return of the market index. The results show that the Monday effect is negative and the Friday effect is positive for excess returns of MSCI Japan, MSCI Asian ex-Japan and MSCI Golden Dragon, which is consistent with Dubois and Louvet (1996), and both the Monday effect and Friday effect are negative for the excess return of MSCI world. There is no evidence of significant serial correlation shown in both with and without the weekday effect residual, and the large Q-statistics for all the residual series of the market indices imply the GARCH effect. To estimate the dynamics of the daily market volatility, we employed both fitted GARCH and EGARCH determined by the best fits of the data. It is found that the week-day effect does not greatly affect the GARCH (or EGARCH) estimation results for all the market indices, and the GARCH models without the day of the week effect yields lower Q-statistics for squared standardized residuals (the results are not reported, but available upon request). So we apply the conditional variance generated by the GARCH models to the estimation of volatilitytiming factor models.

We focus on the estimations of the volatility timing coefficients. We have estimated different specification of Equation (9) for both the CPF funds and non-CPF funds, namely 1) the single-index model without currency risk effect; 2) three-index model without currency risk effect; 3) single-index model with currency risk effect; and 4) three-index model with currency risk effect. The single-index model is the market excess return of a traditional CAPM model. The single-index model with currency risk follows an international CAPM model which includes the market excess return and currency deviation to the excess return of funds. The three-index models with and without currency risk include SMB and HML as two additional factors. In order to exclude the possible multicollinearity among the explanatory variables, we have regressed the SMB, HML and excess return of real currency change on the excess of market separately and then derived the orthogonalized SMB, HML and excess return of real currency change by adding the constant to the corresponding regression residuals. Due to

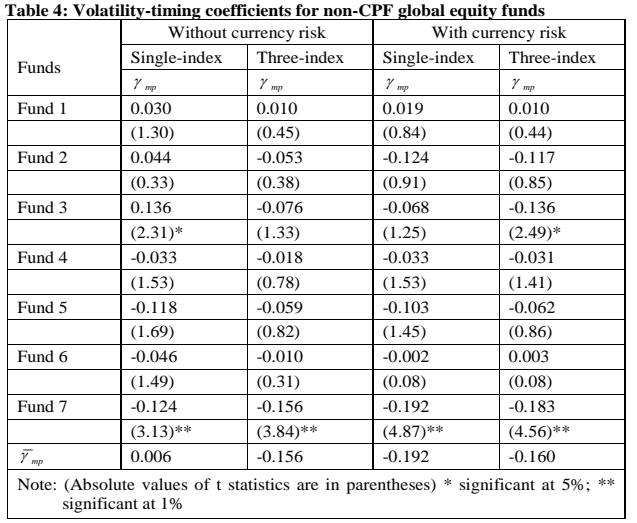

Table 5: Volatility-timing for Asian ex-JP equity funds under CPF Investment Scheme

\begin{tabular}{|c|c|c|c|c|}
\hline \multirow{3}{*}{ Funds } & \multicolumn{2}{|c|}{ Without currency risk } & \multicolumn{2}{|c|}{ With currency risk } \\
\hline & Single-index & Two-index & Single-index & Two-index \\
\hline & $\gamma_{m p}$ & $\gamma_{m p}$ & $\gamma_{m p}$ & $\gamma_{m p}$ \\
\hline \multirow[t]{2}{*}{ Fund 1} & 0.082 & 0.08 & 0.081 & 0.079 \\
\hline & $(3.16)^{* *}$ & (3.14)** & $(3.14)^{* * *}$ & $(3.12)^{* *}$ \\
\hline \multirow[t]{2}{*}{ Fund 2} & -0.06 & -0.058 & -0.061 & -0.059 \\
\hline & -1.26 & -1.22 & -1.29 & -1.26 \\
\hline \multirow{2}{*}{ Fund 3} & -0.003 & -0.004 & -0.002 & -0.003 \\
\hline & -0.1 & -0.13 & -0.07 & -0.1 \\
\hline \multirow[t]{2}{*}{ Fund 4} & 0.015 & 0.017 & 0.012 & 0.014 \\
\hline & -0.38 & \begin{tabular}{|c|}
-0.43 \\
\end{tabular} & -0.31 & -0.35 \\
\hline \multirow[t]{2}{*}{ Fund 5} & 0.02 & 0.022 & 0.017 & 0.018 \\
\hline & -0.68 & -0.73 & -0.6 & -0.64 \\
\hline \multirow[t]{2}{*}{ Fund 6} & 0.1 & 0.099 & 0.099 & 0.098 \\
\hline & $(2.64) * *$ & (2.61)** & $(2.62)^{* *}$ & $(2.60) * *$ \\
\hline \multirow[t]{2}{*}{ Fund 7} & 0.035 & 0.037 & 0.033 & 0.035 \\
\hline & -0.89 & \begin{tabular}{|l|l|}
-0.94 & -1 \\
\end{tabular} & -0.85 & -0.9 \\
\hline \multirow[t]{2}{*}{ Fund 8} & 0.118 & 0.118 & 0.116 & 0.116 \\
\hline & $(2.65)^{* *}$ & (2.65)** & $(2.63)^{* * *}$ & $(2.62)^{* *}$ \\
\hline \multirow[t]{2}{*}{ Fund 9} & 0.059 & 0.061 & 0.058 & 0.06 \\
\hline & -1.43 & -1.49 & -1.4 & -1.46 \\
\hline \multirow[t]{2}{*}{ Fund 10} & 0.102 & 0.102 & 0.098 & 0.099 \\
\hline & (3.54)** & (3.57)** & $(3.57)^{* * *}$ & $(3.59)^{* *}$ \\
\hline $\bar{\gamma}_{m p}$ & 0.101 & 0.0998 & 0.0985 & 0.098 \\
\hline
\end{tabular}

Table 6: Volatility-timing coefficients for non-CPF global equity funds

\begin{tabular}{|l|l|l|l|l|}
\hline \multirow{2}{*}{ Funds } & \multicolumn{2}{|c|}{ Without currency risk } & \multicolumn{2}{c|}{ With currency risk } \\
\cline { 2 - 5 } & Single-index & Three-index & Single-index & Three-index \\
\cline { 2 - 5 } & $\gamma_{m p}$ & $\gamma_{m p}$ & $\gamma_{m p}$ & $\gamma_{m p}$ \\
\hline Fund 1 & 0.124 & 0.124 & 0.121 & 0.121 \\
\hline & $(2.65)^{* *}$ & $(2.64)^{* *}$ & $(2.62)^{* *}$ & $(2.61)^{* *}$ \\
\hline Fund 2 & 0.085 & 0.086 & 0.084 & 0.086 \\
\hline & $(2.12)^{*}$ & $(2.16)^{*}$ & $(2.11)^{*}$ & $(2.16)^{*}$ \\
\hline Fund 3 & 0.057 & 0.058 & 0.057 & 0.057 \\
\hline & -1.69 & -1.71 & -1.68 & -1.7 \\
\hline Fund 4 & -0.017 & -0.015 & -0.017 & -0.015 \\
\hline \multicolumn{7}{|l}{} & -0.62 & -0.56 & -0.62 & -0.56 \\
\hline $\bar{\gamma}_{m p}$ & 0.105 & 0.105 & 0.105 & 0.104 \\
\hline $\begin{array}{l}\text { Note: (Absolute values of t statistics are in parentheses) } \\
\text { significant at 1\% significant at 5\%; }\end{array}$ \\
\hline
\end{tabular}

Table 7: Volatility-timing for Greater China equity funds under CPF Investment Scheme

\begin{tabular}{|c|c|c|c|c|}
\hline \multirow{3}{*}{ Funds } & \multicolumn{2}{|c|}{ Without currency risk } & \multicolumn{2}{|c|}{ With currency risk } \\
\hline & Single-index & Two-index & Single-index & Two-index \\
\hline & $\gamma_{m p}$ & $\gamma_{m p}$ & $\gamma_{m p}$ & $\gamma_{m p}$ \\
\hline \multirow[t]{2}{*}{ Fund 1} & 0.109 & 0.106 & 0.11 & 0.107 \\
\hline & $(3.37)^{* *}$ & $(3.28)^{* *}$ & $(3.41)^{* *}$ & $(3.32)^{* *}$ \\
\hline \multirow[t]{2}{*}{ Fund 2} & -0.055 & -0.051 & -0.054 & -0.05 \\
\hline & -1.74 & -1.64 & -1.71 & -1.6 \\
\hline \multirow[t]{2}{*}{ Fund 3} & 0.024 & 0.021 & 0.026 & 0.023 \\
\hline & -0.77 & -0.68 & -0.87 & -0.78 \\
\hline \multirow[t]{2}{*}{ Fund 4} & 0.146 & 0.142 & 0.148 & 0.145 \\
\hline & $(4.91)^{* *}$ & $(4.81)^{* *}$ & $(5.17)^{* *}$ & $(5.09)^{* *}$ \\
\hline \multirow[t]{2}{*}{ Fund 5} & 0.119 & 0.116 & 0.119 & 0.116 \\
\hline & $(4.09)^{* *}$ & $(4.00)^{* *}$ & $(4.08)^{* *}$ & $(3.99)^{* *}$ \\
\hline $\bar{\gamma}_{m p}$ & 0.125 & 0.121 & 0.126 & 0.123 \\
\hline
\end{tabular}


space limitation, we report in Tables 1-8 only the volatility-timing estimates for the four CPF and non-CPD funds.

The results in Tables 1-8 show that most of Japanese equity funds and global equity funds under the CPF investment scheme have a negative volatility-timing coefficient, and with the inclusion of currency risk exposure the number of negative

Table 8:Volatility-timing coefficients for non-CPF Greater China equity funds
\begin{tabular}{|l|l|l|l|l|}
\hline \multirow{3}{*}{ Funds } & \multicolumn{2}{|c|}{ Without currency risk } & \multicolumn{2}{c|}{ With currency risk } \\
\cline { 2 - 5 } & Single-index & Two-index & Single-index & Two-index \\
\cline { 2 - 5 } & $\gamma_{m p}$ & $\gamma_{m p}$ & $\gamma_{m p}$ & $\gamma_{m p}$ \\
\hline Fund 1 & 0.179 & 0.181 & 0.179 & 0.18 \\
\hline & $(3.22)^{* *}$ & $(3.25)^{* *}$ & $(3.22)^{* *}$ & $(3.25)^{* *}$ \\
\hline Fund 2 & -0.022 & -0.024 & -0.02 & -0.021 \\
\hline & -0.72 & -0.75 & -0.66 & -0.68 \\
\hline $\bar{\gamma}_{m p}$ & 0.179 & 0.181 & 0.179 & 0.18 \\
\hline $\begin{array}{l}\text { Note: (Absolute values of t statistics are in parentheses) * significant at 5\%; ** } \\
\text { significant at 1\% }\end{array}$
\end{tabular}
significant at $1 \%$

and significant volatility-timing estimates increase. This implies that, when the market becomes more volatile, these fund managers will decrease funds' exposure to the market volatility to increase their performance. Inclusion of currency risk exposure improves the model specification. It is also found that these funds managers have stronger ability in risk management, as their average volatility-timing coefficient is more negative than that of non-CPF funds. For the Asian equity funds and the Greater China funds, only 4 out of 10 and 3 out of 5 funds show a significant volatility-timing estimate but all positive, which implies these funds fail to demonstrate any volatility-timing ability. Those funds may increase market exposure when the market is volatile, which in turn decrease their performance. One possible explanation is the lack of diversification for regional funds in Asia.

\section{CONCLUDING REMARKS}

In this paper we examine the volatility-timing performance of Singapore-based funds under the CPF Investment Scheme and non-CPF linked funds by taking into account of the currency risk effect on internationally managed funds. We employ the GARCH models and modified factor models to capture the response of funds to the market abnormal conditional volatility including the day of the week effect. The results show that volatility timing is one of the factors contributing to the excess return of funds. However, funds' volatility-timing seems to be country-specific. Most of the Japanese equity funds and global equity funds under CPF investment scheme are found to have the ability of volatility timing, but the Asian equity funds and the Greater China funds failed to demonstrate any volatility-timing ability. Those funds may increase market exposure when the market is volatile, which in turn decrease their performance. Moreover, there is no evidence that funds under CPF Investment Scheme show a better group performance of volatility timing.

\section{REFERENCES}

Busse, J. A. (1999). Volatility Timing in Mutual Funds: Evidence from Daily Returns, The Review of Financial Studies 12, 1009-1041.

Dubois, M. and P. Louvet (1996). The day-of-the-week Effect: the International Evidence, Journal of Banking \& Finance 20, 1463-1484.

Fama, E. F. and K. R. French (1993). Common Risk Factors in the Return on Stocks and Bonds, Journal of Financial Economics 33, 3-56.

Jensen, M. C. (1969). Risk, the Pricing of Capital Assets, and the Evaluation of Investment Portfolios, Journal of Business 42, 167-247.

Jensen, M. C. (1972). Optimal Utilization of Market Forecasts and the Evaluation of Investment Performance. In G. P. Szego, Karl Shell (eds), Mathematical Methods In Investment and Finance. NorthHolland Publishing Company.

Koh, B. S. K., O. S. Mitchell, T. Tanuwidjaja and J. Fong (2007). Investment Patterns in Singapore's Central Provident Fund System, Journal of Pension Economics and Finance 7, 37-65.

Lim, G.C. (2005).Currency Risk in Excess Equity Returns: a Multi Time-varying Beta Approach, Journal of International Financial Markets, Institutions \& Money 15, 189-207.

McAleer, M. (2005). Automated inference and learning in modeling financial volatility. Econometric Theory, 21, 232-261

Merton, R. C., and R. D. Henriksson (1981). On Market Timing and Investment Performance II: Statistical Procedures for Evaluating Forecasting Skills, Journal of Business 54, 513-534.

Sharpe, W. F. (1966). Mutual Fund Performance, Journal of Business 39, 119-138.

Treynor, J. L. and Kay K. Mazuy (1965). Can Mutual Funds Outguess the Market? Harvard Business Review 44, 131-136. 